\title{
An analysis of the Indicators of Regional Economy Spatial Development in the Leningrad Region of Russia
}

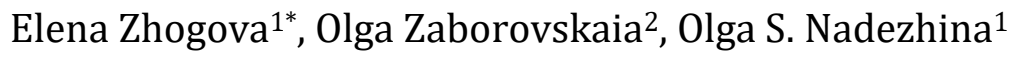 \\ ${ }_{1}^{1}$ Peter the Great St. Petersburg Polytechnic University, Polytechnicheskaya Street, 29, St. Petersburg \\ 195251, Russia \\ 2 State Institute of Economics, Finance, Law and Technologies, Roschinskaya Street, 5, Gatchina 188309, \\ Russia
}

\begin{abstract}
The unevenness of regional spatial development is a relevant subject of research in Russia and internationally. This study is intended to substantiate a modified methodology based on the cluster approach for identifying regional cluster groups and the methods for determining priority development areas for clusters of small and medium-sized enterprises. This study identifies the priority sectors for the development of the Leningrad region, including manufacturing, construction, wholesale and retail trade, electricity, gas and water production, transport and communications, agriculture, hunting and forestry, operations with real estate, and rental services. These industries are ranked according to their degree of importance (with high and maximum degree of importance). The results of the study enable the identification of sectors and enterprises that have the greatest potential and require government support. The proposed algorithm can be applied to any territorial entity and makes it possible to modify the set of statistical data for the required adjustments, thus contributing to the spatial development of the region.
\end{abstract}

Keywords: Cluster approach; Indicators; Region; Spatial development

\section{Introduction}

The unevenness of regions' spatial development has been the subject of research in many international and Russian studies (Kasala, 1996; Argüelles et al., 2000). This unevenness is reflected in different levels of industrial development and must be taken into account when working on regional industrial policy (Maier, 1998; Bruszt and Palestini, 2016; Polyanin et al., 2020). When choosing priority areas for industrial development, it is important to consider the ongoing processes of agglomeration and digitalization, the positions of major industrial enterprises, growth poles, and the industries that have the greatest economic potential (Lyakin, 2014). Consequently, a factor analysis of regional economy spatial development makes it possible to identify the uneven development of various industries and to highlight the priority ones.

One common theory that takes into account significant factors and obtains results correlated with economic realities is the cluster theory. Based on the modification of methods for assessing clusters' efficiency and the effects of production localization (agglomeration), the cluster theory makes it possible to determine the uneven development 
of the branches of the regional economy and identify the priority areas. The purpose of this study is to analyze the indicators of regional spatial development and identify the priority sectors of the regional economy in the Leningrad region of the Russian Federation.

There are many scientific works in the framework of the territorial-sector approach that aim to determine the causes of uneven spatial distribution of production resources and economic activities (Maier, 1998; Karayel, 2017). In the age of globalization, some socioeconomic factors affecting the development of the regions have undergone changes and new factors have emerged, such as digitalization, virtual space, and integration into the global economy. There are certain contradictions between the global expansion of sales markets and the increased unevenness of regional development. Some researchers propose the idea of inclusive social development of territories and communication infrastructure (Glukhov and Korobko, 2003).

One of the key theories explaining the patterns of spatial development of territories is Thünen's theory. It is based on the concept of an economy as an isolated system that considers two major factors - the rent and the distance to the place of sale (Limonov et al., 2017). In Launhardt's model, Thünen's ideas are represented in graphs. Launhardt's triangle is based on the location of the factory, the location of the resources, and the location of outlets. Weber complemented Launhardt's model with a description of the influence of labor market on the location of the factory. Hotelling's model adds the factor of competitiveness to Weber's model. Hotelling's model adds the following parameter: prices are related to the level of constant marginal costs, which are the same for all companies. Cristalller's theory of central places contributes to the theories discussed above. The theory is focused on the formation of "central places" in cities in the form of hexagons that cover the entire territory (Limonov et al., 2017). This theory is an attempt to formulate a hypothesis about the regular location of the cities relative to each other, but it does not take into account the real situation and has a large number of inaccuracies. Lesch continued to develop these theories based on the location of cities (Limonov et al., 2017). His model outlines the conditions for continuous industrial expansion and free competition, with an increasing number of highly profitable factories.

Alonso's spatial model of the city introduced the profitability function for companies and the utility function for households, as well as the other factors such as the size of the enterprise and its distance from the center. Alonso used his model to analyze the external economic environment in terms of location and population density in the city (Limonov et al., 2017). A significant contribution to the understanding of spatial development was made by the authors of regional growth models based on demand: The Harrod-Domar model, Thirlwall's, model by V.V. Leontiev.

Theories of absolute and relative advantages are focused on the issue of regional specialization and trade; one example is the model developed by David Ricardo (Kistanov and Kopylov, 2003; Limonov et al., 2017). A modified version of this model introduced an indicator of scientific and technological progress in the form of a new knowledge factor. This approach is reflected in the production model of Robert Solow, in which technological progress is considered independent of capital and labor (Limonov et al., 2017). The theory of competitive advantages is based on the cluster approach and determines the productivity of production factors and their returns (capital, labor, natural resources), as well as the possibility of support measures for firms to develop competitive advantages (Limonov et al., 2017).

Within the framework of the cluster approach, Michael Potrer identified two competing forces affecting the regional economy at the regional level: convergence and agglomeration. Convergence leads to a decrease in the industry's growth rat, despite stable or high 
economic activity. Agglomeration gives an increasing return on activity, either from one industry (localization) or from diversification at the regional level (urbanization). Both competing forces influence the regional economy; convergence is reflected at the level of an individual industry or within a narrow group of industries, while agglomeration affects the entire complex of clusters. These studies confirmed the hypothesis that within the framework of strong cluster groups, there is a higher rate of employment and wages and a greater number of firms not only in the region but also in adjacent territories (Ferova et al., 2018).

This study is based on the approach regarding agglomeration influence (Maskell and Malmberg, 2002). It also takes into account the activity of cluster groups and the priority areas for their development. The authors aim to identify priority sectors of the regional economy for the Leningrad region.

\section{Methods}

The approach proposed by the authors is a synthesis of the modified methodology for identifying cluster groups in the regional economy proposed by Zhabin (2015) and the methodology for determining priority areas for the development of clusters of small and medium-sized enterprises proposed by Kiselev et al. (2011). These techniques are based on a methodological approach to identifying clusters.

At the first stage, cluster groups are identified according to the methodology of the Institute for Strategy and Competitiveness of Harvard Business School (Porter, 1998; Kiselev et al., 2011). The proposed methodology is comprised of a sequence of actions for the selection of industrial enterprises as priority areas of industrial policy. It allows the authors to concentrate financial resources at certain points of growth, which will contribute to the industrial development of the region as a whole due to the combined effect of agglomeration and convergence.

At the first stage, 16 types of economic activities are distinguished based on the Russian classifier; then, the decomposition of types of economic activities in industries is carried out in accordance with the methodology described by Tyutyukin et al. (2014). The importance of industries is calculated based through an aggregated list of indicators: employment statistics, statistics of the shipped products, and uniqueness according to the method proposed by Kiselev et al. (2011). The industries are ranked on the basis of employment statistics and shipping statistics. The starting point of this technique is the calculation of the localization coefficient. With a value greater than 1 , the cluster is considered important, which indicates economic agglomeration.

The localization factor is calculated using the following equation:

$$
\mathrm{LQ}=\frac{E m p_{\text {ig }}}{E m p_{\mathrm{g}}} / \frac{E m p_{i}}{E m p}=\frac{E m p_{\text {ig }}}{E m p_{i}} / \frac{E m p_{g}}{E m p}
$$

where LQ is the localization coefficient, $\mathrm{Emp}_{\mathrm{ig}}$ is the number of people employed in industry $\mathrm{i}$ in region $\mathrm{g}, \mathrm{Emp}_{\mathrm{g}}$ is the total number of people employed in region $\mathrm{g}, \mathrm{Emp}_{\mathrm{i}}$ is the number of people employed in industry $\mathrm{i}$, and Emp is the total number of employees.

The obtained values were used by Tyutyukina et al. (2014) to rank cluster groups in the city of Moscow similar calculations were made for the Leningrad region according to type of economic activity.

At the next stage, the criteria for identifying important cluster groups developed by the European Cluster Observatory were used (if the localization coefficient is equal or greater than 2, the region is among the top $10 \%$ of leading indicators in terms of "Size" and "Focus" - clusters corresponding to at least two threshold values are assigned to important 
ones). In our methodology, the same mechanism is applied for types of economic activity. The localization coefficient and the indicators "Focus" and "Size" were calculated using the following formulas.

The size of a cluster group is calculated using the following equation:

$$
\text { Size }=\frac{\mathrm{Emp}_{\mathrm{ig}}}{\mathrm{Emp}_{\mathrm{i}}}
$$

where Size is the size of the cluster group $i, E m p_{i g}$ is the number of people employed in cluster group $i$ in region $g$, and $E m p_{i}$ is the number of people employed in cluster group $i$.

The focus of a cluster group is calculated through the following equation:

$$
\text { Focus }=\frac{\text { Emp }_{\mathrm{ig}}}{\mathrm{Emp}_{\mathrm{g}}}
$$

where Focus is the focus of the cluster group $i, E m p_{i g}$ is the number of people employed in cluster group $i$ in region $g$, and $E m p_{g}$ is the number of people employed in cluster group $g$.

Based on the data obtained, the cumulative indicator of the degree of importance of the industry is calculated using statistics on employment and the shipped products, as well as statistics on the turnover of the companies that were added in our study.

The cumulative significance indicator is comprised of the following weights: $3 / 5$ of the cluster group indicator in terms of localization coefficient, focus, and size calculated according to employment statistics; $1 / 5$ of the cluster group indicator in terms of localization coefficient, focus, and size calculated according to statistics of the shipped products (work performed or services rendered); and 1/5 of the cluster group uniqueness indicator.

The value of the employment indicator, which forms the basis of the list of significant clusters, is the same as for calculating the list of priority sectors (types of economic activity). The indicators calculated by the statistics of the company's turnover are corrective. Furthermore, according to the methodology proposed by Kiselev et al. (2011) and Zhabin (2015), an additional 1 point is added if a cluster group corresponds to three threshold values, 0.5 points are added with correspondence to two values, and 0 points are added in all other cases.

The uniqueness indicator reflects the degree of unevenness in regional employment and is calculated in values ranging from 0 to 1 . In this study, the uniqueness coefficient is calculated based on the localization coefficient according to employment indicators. Having calculated the average value of the localization coefficient for all types of activity, we can calculate the deviation of the values of this coefficient from the average value, and this deviation value is used to adjust the indicator of the importance of economic activity (Kudryavtseva and Zhabin, 2014; Kudryavtseva et al., 2020). Then, the comparison of the degrees of importance is made according to the statistics of employment and the turnover of companies by the leading clusters and, in our case, by the types of economic activity (with maximum and high significance).

\section{Results and Discussion}

The localization coefficient in this study is calculated through several indicators, including indicators of employment in the industry and indicators of the company's turnover in the industries under study. In the original methodology by Kiselev et al. (2011), cluster groups were determined and the localization coefficient was calculated based on employment indicators and the amount of products shipped by the industry itself. However, the statistical data do not allow us to determine the volume of products produced by the 
selected industries; hence, the indicator of shipped products shipped was replaced with the indicator of the companies' turnover to reflect the business activity of a particular industry.

For a more detailed analysis of the localization of the activities (industries) in the Leningrad Region, we present the obtained data from 2014 and 2018 in Table 1.

Table 1 The localization coefficient (LQ) of industries in terms of employment in the Leningrad region in 2014 and 2018

\begin{tabular}{lcc}
\hline \multicolumn{1}{c}{ Industries } & LQ & LQ \\
& 2014 & 2018 \\
\hline Financial activities & 0.376 & - \\
\hline Mining & 0.514 & 0.454 \\
\hline Education & 0.707 & 0.803 \\
\hline Public administration and military security; social insurance & 0.730 & 0.773 \\
\hline Health care and social services & 0.748 & 0.763 \\
\hline Real estate transactions; rental services & 0.875 & 1.139 \\
\hline Provision of other utilities and social services & 0.906 & 0.986 \\
\hline Wholesale and retail trade; repair of vehicles; household goods and personal & 0.993 & \\
items & & 1.020 \\
\hline Agriculture, hunting, and forestry & 1.042 & 1.311 \\
\hline Transport and communications & 1.067 & $1.094^{*}$ \\
\hline Hotels and restaurants & 1.070 & 0.998 \\
\hline Production and distribution of electricity, gas, and water & 1.214 & 1.307 \\
\hline Manufacturing industries & 1.293 & 1.190 \\
\hline Construction & 1.341 & 1.303 \\
\hline Administrative activities and related services & - & 0.973 \\
\hline
\end{tabular}

The results of the localization coefficient (LQ) of industries in terms of employment in the Leningrad region in 2014, as obtained by Zhogova (2019), can be compared with the data from 2018. The results obtained indicate the prevailing position of certain industries in the Leningrad region along with the dynamics of their business activity. It should be noted that data for the "Transport and communications" industry differ in 2014 compared to in 2018, since in 2018 "Transport" and "Communications" were considered separately and we did not take the latter into account in 2018. The statistical information for 2018 does not contain all data regarding the financial activity in the region.

In accordance with to the calculation algorithm for the significance of the cluster groups, the indicators of the localization coefficient in terms of employment are updated through the calculation of the localization indicator of the companies' turnover in the Leningrad region and the uniqueness of the industry among the sectors under study. The calculation in 2018 was carried out with the indicator of "companies' turnover" since statistical data on the shipment of products are only available for a few sectors of the Leningrad region. Further analysis will be conducted only for 2018 since the data for 2014 are calculated according to different indicators. However, the results obtained will be compared to summarize the research findings.

The uniqueness indicator is based on the localization coefficient in terms of employment. Having calculated the average value of the localization coefficient for all types of activity, we calculate the deviation of the values of this coefficient based on the average value; this deviation value is used to adjust the indicator of the significance of economic activity. The dynamics of the uniqueness indicator for 2018 are shown in Figure 1. 


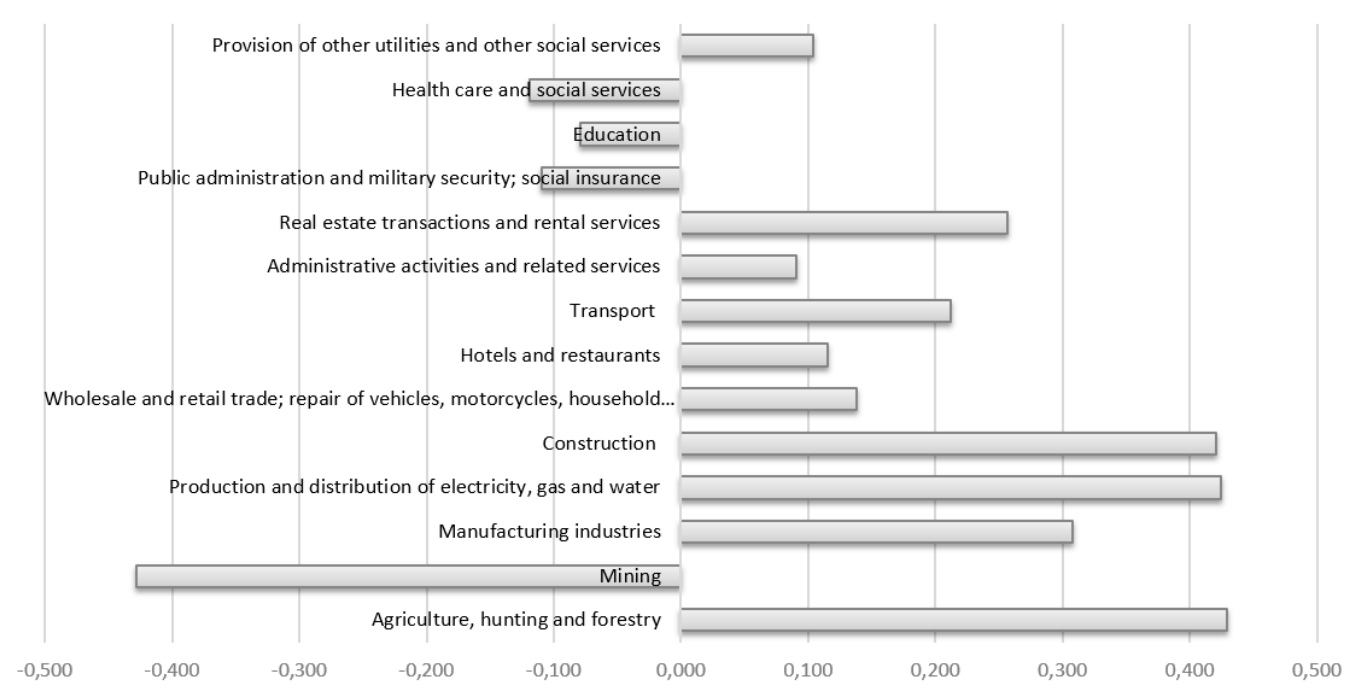

Figure 1 Indicators of uniqueness in 2018 (in terms of employment)

Furthermore, the aggregate indicator of the degree of importance of the industries of the Leningrad Region is calculated according to statistics of employment and turnover in organizations, taking into account the uniqueness coefficient (Table 2).

Table 2 Indicators of the importance of industries in 2018

\begin{tabular}{lccc}
\hline \multicolumn{1}{c}{ Industries } & $\begin{array}{c}\text { Significance index } \\
\text { for shipped } \\
\text { products }\end{array}$ & $\begin{array}{c}\text { Significance } \\
\text { index for } \\
\text { employment }\end{array}$ & $\begin{array}{c}\text { Signifi } \\
\text { cance } \\
\text { index }\end{array}$ \\
\hline Agriculture, hunting and forestry & 0.399 & 0.850 & 1.334 \\
\hline Mining & 0.017 & 0.279 & 0.211 \\
\hline Manufacturing industries & 0.435 & 0.823 & 1.319 \\
\hline $\begin{array}{l}\text { Production and distribution of electricity, gas and water } \\
\text { building }\end{array}$ & 0.346 & 0.810 & 1.241 \\
\hline Construction & 0.295 & 0.859 & 1.238 \\
\hline Wholesale and retail trade; repair of vehicles; household & 0.183 & 0.736 & 0.947 \\
goods and personal items & 0.110 & 0.620 & 0.753 \\
Hotels and restaurants & 0.286 & 0.712 & 1.041 \\
\hline Transport & 0.222 & 0.601 & 0.842 \\
\hline Administrative activities and related services & 0.205 & 0.709 & 0.966 \\
\hline Real estate transactions and rental services & 0.234 & 0.492 & 0.705 \\
\hline Public administration and military security; social insurance & 0.054 & 0.523 & 0.562 \\
\hline Education & 0.118 & 0.491 & 0.586 \\
\hline Health care and social services & 0.095 & 0.612 & 0.727 \\
\hline Provision of other utilities and other social services & &
\end{tabular}

According to this methodology, if a significant cluster group corresponds to three threshold values (in terms of localization, focus, and size in accordance with the employment statistics), an additional 1 point is added; if two values correspond, 0.5 points are added; and 0 points are added in all other cases. This adjustment makes it possible to reveal the industries' importance in the Leningrad region in 2018 and complete the final stage of the described methodology-that is, to distribute the significant industries according to their degree of importance (with high and maximum importance) (see Table 
4). To analyze the results obtained, we can compare them with the data of 2014 (see Table 3).

Table 3 Comparison of the degree of importance by type of economic activity in 2014

\begin{tabular}{lll}
\hline \multirow{2}{*}{ Indicator } & \multicolumn{2}{c}{ Degree of importance according to the statistics of shipped products, } \\
\cline { 2 - 3 } services
\end{tabular}

Table 4 Comparison of the degree of importance by type of economic activity in 2018

\begin{tabular}{llll}
\hline \multicolumn{2}{c}{ Indicator } & \multicolumn{2}{c}{$\begin{array}{c}\text { Degree of importance according to the statistics of shipped products, } \\
\text { services }\end{array}$} \\
\cline { 2 - 4 } & Maximum & \multicolumn{1}{c}{ Maximum } & \multicolumn{1}{c}{ High } \\
\hline $\begin{array}{l}\text { Significance } \\
\text { by } \\
\text { employment } \\
\text { statistics }\end{array}$ & High & construction & $\begin{array}{l}\text { Wholesale and retail trade; } \\
\text { production and distribution of } \\
\text { electricity, gas and water }\end{array}$ \\
\hline
\end{tabular}

Thus, the priority sectors of the region are the following: manufacturing; construction; wholesale and retail trade; production and distribution of electricity, gas, and water; transport and communications; agriculture, hunting and forestry; real estate transactions; and rental services. The method proposed for analyzing the spatial development of the regional economy takes into account the influence of agglomeration. The authors rely on $\mathrm{M}$. Porter's cluster approach and the importance of agglomeration. Agglomeration provides an opportunity to leverage increasing returns from activities either from a single industry (localization) or from regional diversity (urbanization). Both factors affect the regional economy: convergence is reflected at the level of the separate industry, while agglomeration affects the entire complex of clusters (Zhabin, 2015; Skhvediani and Sosnovskikh, 2020).

When determining priority areas for industrial development, we should take into account the key industries in the region and the location of the enterprises. The region implements industrial policy developed by the federal center that relies on existing industrial potential (Rodionov et al., 2018b). In the conditions of limited state funds, it is necessary to identify the industries and enterprises that are of greatest importance for the development of the region and advocate for their support. The proposed technique makes it possible to implement this program.

The algorithm for calculating the relevant indicators allows us to change the set of statistical data and adjust the indicators of industries' localization in accordance with employment statistics. In our case, the corrective indicator in the research of 2014 was the volume of manufactured products, and in the analysis of 2018, we used the indicator of the company's turnover. The methodology by Kiselev et al. (2011) and Zhabin (2015) was 
developed to assess the effectiveness of cluster groups, but this study showed that this methodology can also be applied to assess the business activity of the regional industries without focusing on the cluster groups, which can be the basis for identifying the priority areas of the development of both the industrial policy and the infrastructure of the region.

\section{Conclusions}

Spatial development theories focus on the factors of the spatial economic development of specific regions (Theodoropoulou et al., 2009). Originally, spatial development models described the relationship between the location of entities and various types of costs (time costs, financial costs, transportation costs, etc.). However, with globalization processes, the impact of these factors on regional economies has changed, and new factors of influence have emerged. The most productive method for the analysis of spatial development is the cluster approach, which takes into account the location of enterprises and their economic efficiency. With strongly clustered connections, there is a high level of employment and wages and a greater number of businesses; therefore, it is advisable for regional industrial policy to focus on the support of such industrial groups.

For the analysis of spatial development in the Leningrad region, we have applied a method that identifies the priority areas for the development of clusters of small and medium-sized enterprises with the relevant modification of the indicators used. Using this technique made it possible to identify the most significant industries of the region. The priority sectors of the region are the following: manufacturing; construction; wholesale and retail trade; production and distribution of electricity, gas and water; transport and communications; agriculture, hunting and forestry; real estate transactions; and rental services.

So, the development of the infrastructure of industrial enterprises belonging to priority sectors can act as a significant contribution to the regional economy and industrial policy, as is argued in many works (Gradov et al., 2003; Granberg, 2004; Rodionov et al., 2018a). Expanding the number of industrial companies and providing them with the opportunities for development will contribute to the growth of human capital (Shabunina et al., 2018; Rodionov et al., 2018b) and increase the number of jobs, which will consequently reduce the unevenness of regional development.

In conclusion, it should be noted that all spatial models considered in this study need to be further updated and should take into account additional factors for effective regional development (Črešnar et al., 2020). Factors such as the effectiveness of industrial sectors and the number of people employed are important for economic feasibility analysis and can ensure the development of the most efficient industrial policy.

\section{Acknowledgements}

This research work was supported by the Academic Excellence Project 5-100 implemented by Peter the Great St. Petersburg Polytechnic University.

\section{References}

Argüelles, M., Benavides, C., Pérez-Bustamante, G., 2000. The Protected Designations of Origin as a Strategy of Endogenous Regional Development. In: 40 th Congress of the European Regional Science Association: "European Monetary Union and Regional Policy", August 29-September 1, 2000, Barcelona, Spain 
Bruszt, L., Palestini, S., 2016. Regional Development Governance. In: The Oxford Handbook of Comparative Regionalism, Börzel, T.A., Risse, T. (eds.), Oxford University Press, New York, pp. 374-404

Črešnar, R., Potocan, V., Nedelko, Z., 2020. Speeding Up the Implementation of Industry 4.0 with Management Tools: Empirical Investigations in Manufacturing Organizations. Sensors, Volume 20(12), pp. 1-25

Ferova, I.S., Kozhinova, T.V., Shorokhov, R.G., Tanenkova, E.N., Skarpetina, E.V., 2018. Industrial Clusters and Their Role in the Development of Industrial Policy in the Region. Moscow: INFRA-M Publishing House

Glukhov, V.V., Korobko S.B., 2003. Economics of Knowledge. Handbook. Publishing House Piter, St. Petersburg

Gradov, A.P., Mednikov, M.D., Kuzin, B.I., Sokolitsyn, A.S., 2003. Regional Economy: Principles and Models of Managing the Business Climate in the Region. Handbook. Publishing House Peter, St. Petersburg

Granberg, A.G., 2004. Fundamentals of Regional Economy: A Textbook for Universities. Moscow: Publishing house of HSE, Moscow

Karayel, S., 2017. Regional Economic Tendencies of Business Cluster Development. The Journal of Academic Social Science, Volume 5(42), pp. 208-226

Kasala, K., 1996. Regions as Spatial Systems and Regional Development. Acta facultatis rerum naturalium universitatis comenianae: Geographica, Volume 38, pp. 91-107

Kiselev, A.N., Kutsenko, E.S., Karnaukh, A.P., 2011. Determination of Priority Areas for the Formation of Clusters of Small and Medium-Sized Enterprises on the Example of Moscow. In: Network Business and Cluster Technologies, Tretiak, V.P., Sheresheva, M.Y., (ed.), Publishing House of the HSE, Moscow, Russia, pp. 279-302

Kistanov, V.V., Kopylov, N.V., 2003. Regional Economy of Russia: Textbook. Finance and Statistics, Moscow

Kudryavtseva, T., Kulagina, N., Lysenko, A., Berawi, M.A., Skhvediani, A., 2020. Developing Methods to Assess and Monitor Cluster Structures: The Case of Digital Clusters. International Journal of Technology, Volume 11(4), pp. 667-676

Kudryavtseva, T.Y., Zhabin, N.P., 2014. Formation of an Algorithm for Identifying Clusters in the Economy of the Region. SPbSPU Scientific and Technical Bulletin, Volume 3(197), pp. $124-131$

Limonov, L.E., Zhikharevich, B.S., Batrachev, A.R., Berezin, M.P., Varlamova, O.D., Vlasova, T.V., Zhunda, N.B., Zaostrovtsev, A.P, Kadochnikov, D.V., Karelina, I.A., Kolchinkaja, E.E., Lebedeva, E.A., Nesena, M.V., Oding, N.J., Pokrovskij, D.A., Rusetskaja, O.V., Savulkin, L.I., Tabachnikova, D.A., Shevchuk, D.V., 2017. Regional Economy and Spatial Development. $2^{\text {nd }}$ Edition. Moscow, Russia: Yurayt Publishing House

Lyakin A.N., 2014. Economic Policy: A Textbook and a Workshop for Bachelor's and Master's Degree. $1^{\text {st }}$ Edition. Moscow, Russia: Yurayt Publishing House

Maier, G., 1998. History, Spatial Structure, and Regional Growth: Lessons for Policy Making. In: SRE-Disc, Institute for Multilevel Governance and Development, Department of Socioeconomics, Vienna University of Economics and Business, Volume 63, pp 1-31

Maskell, P., Malmberg, A., 2002. The Elusive Concept of Localization Economics: Towards a Knowledge-based Theory of Spatial Clustering. Ukendt Publiceringskanal, Volume 34(1), pp. 429-449

Polyanin, A., Pronyaeva, L., Pavlova, A., Fedotenkova, O., Rodionov, D., 2020. Integrated Approach for Assessing the Economic Security of a Cluster. International Journal of Technology, Volume 11(6), pp. 1148-1160 
Porter, M.E., 1998. Clusters and the New Economics of Competition. Harvard Business Review, Volume 76 (6), pp. 77-90

Regions of Russia. Socio-economic Indicators 2019. Available Online at https://rosstat.gov.ru/storage/mediabank/1dJJCOvT/Region_Pokaz_2019.pdf

Rodionov, D.G., Konnikov, E.A., Konnikova, O.A., 2018a. Approaches to Ensuring the Sustainability of Industrial Enterprises of Different Technological Levels. Journal of Social Sciences Research, Volume 4 (SI-3), pp. 277-282

Rodionov, D.G., Kudryavtseva, T.J., Skhvediani, A.E., 2018b. Human Development and Income Inequality as Factors of Regional Economic Growth. European Research Studies Journal, Volume 21(SI-2), pp. 323-337

Shabunina, T.V., Shchelkina, S.P., Rodionov, D.G., 2018. Regional Habitat as a Factor of the Human Capital Assets Development in Russian Regions. Journal of Social Sciences Research, Volume 4 (SI-3), pp. 313-317

Skhvediani, A., Sosnovskikh, S., 2020. What Agglomeration Externalities Impact the Development of the Hi-tech Industry Sector? Evidence from the Russian Regions. International Journal of Technology, Volume 11(6), pp. 1091-1102

Theodoropoulou, H., Mitoula R., Vamvakari, M., 2009. Sustainable Regional Development. Journal of Social Sciences, Volume 5(2), pp. 80-84

Tyutyukina, E.B., Kapranova, L.D., Sedash, T.N., 2014. Determination of Priority Areas and Investment Support for the Development of the Russian Economy. Journal of Economic Analysis: Theory and Practice, Volume 38(389) pp. 35-49

Zhabin, N.P., 2015. Methodical Bases of Cluster Groups Identification in the Regional Economy. Ph.D. Dissertation, Doctoral Programme, Institute for Regional Economics Problems of the Russian Academy of Sciences, St. Petersburg, Russia

Zhogova, E.V., 2019. Development of Industrial Policy Priorities based on Growth Poles. Ph.D. Dissertation, Doctoral Programme, Peter the Great St. Petersburg Polytechnic University, St. Petersburg, Russia 